\title{
Influence of Sheared Edge on Hydrogen Embrittlement Resistance in an Ultra-high Strength Steel Sheet
}

\author{
Masataka YOSHINO, ${ }^{1) *}$ Yuki TOJI, ${ }^{3)}$ Shusaku TAKAG| ${ }^{3)}$ and Kohei HASEGAWA ${ }^{2)}$ \\ 1) Steel Research Laboratory, JFE Steel Corporation, 1, Kawasaki-cho, Chuo-ku, Chiba, 260-0835 Japan. \\ 2) Steel Research Laboratory, JFE Steel Corporation, 1, Kokan-cho, Fukuyama, Hiroshima, 721-8501 Japan. \\ 3) Steel Research Laboratory, JFE Steel Corporation, 1-1, Minamiwatarida-cho, Kawasaki-ku, Kawasaki, Kanagawa, Japan.
}

(Received on November 22, 2013; accepted on February 19, 2014; originally published in Tetsu-to-

Hagané, Vol. 99, 2013, No. 4, pp. 302-311)

\begin{abstract}
Automotive parts made from steel sheets normally have sheared edges, which have been reported to decrease the hydrogen embrittlement (HE) resistance of ultra-high strength steel (UHSS) sheets. However, the mechanism on the detrimental effect of the sheared edge on HE resistance is not yet clearly understood. In this study, the influence of the edge condition in UHSS sheets on the HE property was investigated using a $1180 \mathrm{MPa}$ grade steel sheet. The HE resistance of specimens with the edges ground or as-sheared was evaluated by the U-bend method. Two types of as-sheared specimens, which had been bent so that either the burnished surface or the fracture surface was the outer side, were prepared. The specimens with the ground edges did not fracture under any conditions. The fracture stress of the fracture surface specimens was significantly lower than that of the burnished surface specimens. Microcracks were observed at the edge of the specimens except for the ground specimens, and larger microcracks were observed in the fracture surface specimens. Fracture stress drastically decreased as the microcrack length increased. The threshold of the stress intensity factor $K$ decreased with increasing diffusible hydrogen content. When the threshold stress intensity factor at each diffusible hydrogen content was defined as $K_{H}$, the fracture condition was described as $K>K_{H}$. The reason why the fracture stress in the as-sheared specimen decreased was considered to be that $K$ increased due to the microcracks introduced by bending.
\end{abstract}

KEY WORDS: delayed fracture; diffusible hydrogen; dual-phase steel; shearing; stress intensity factor.

\section{Introduction}

Ultra-High Strength Steel (UHSS) sheets with tensile strength (TS) over $980 \mathrm{MPa}$ have been applied to automotive parts for weight saving and improvement of the crashworthiness of car bodies. ${ }^{1,2)}$ However, a risk of hydrogen embrittlement fracture called delayed fracture has been reported in high strength steel bolts with TS over 1100 $\mathrm{MPa}^{3)}$ Delayed fracture is considered to be caused by diffusible hydrogen which enters the steel from the environment. Therefore, not only high formability suitable for pressforming of automotive parts, but also sufficient hydrogen embrittlement resistance is required of UHSS sheets.

The factors which cause delayed fracture in press-formed parts are applied strain, residual stress and diffusible hydrogen. Several methods of evaluating the influence of these factors on delayed fracture susceptibility have been reported. ${ }^{4-11)}$ Hosoya et al. reported the hydrogen embrittlement susceptibility of high strength steel sheets which were evaluated by the 4-point bending and U-bend methods. ${ }^{4)}$ Toji et al. systematically investigated the influence of strain, stress and diffusible hydrogen content on hydrogen embrittlement resistance, and suggested a 3-dimensional map concept in

\footnotetext{
* Corresponding author: E-mail: ma-yoshino@jfe-steel.co.jp
}

DOI: http://dx.doi.org/10.2355/isijinternational.54.1416 which the conditions for the occurrence of delayed fracture are evaluated by strain, stress and diffusible hydrogen content. ${ }^{5)}$ Hayashi et al. suggested an evaluation technique in which hydrogen is introduced by a cathodic charge technique into a steel sheet tightened with a bolt after U-bending. ${ }^{6}$ In the report, Hayashi et al. showed that hydrogen cracking occurred remarkably early in specimens without edge grinding as compared with edge-ground specimens.

UHSS sheets are subject to press-forming without edge grinding after blanking by shearing or punching, and as a result, press parts produced from UHSS sheets have sheared or punched edges. ${ }^{12)}$ Therefore, in order to evaluate the hydrogen embrittlement resistance of press-formed automotive parts, it is important to understand the hydrogen embrittlement behavior of UHSS sheets with sheared edges.

In this study, the influence of the edge condition, applied stress, bending strain and diffusible hydrogen content on hydrogen embrittlement resistance in UHSS sheets with sheared edges was investigated in detail. Furthermore, the mechanism of the detrimental effect of the sheared edge on hydrogen embrittlement resistance was discussed.

\section{Experimental Procedure}

The steel used in this study was a $1180 \mathrm{MPa}$ grade ferrite- 
Table 1. Mechanical properties of steel studied.

\begin{tabular}{ccc}
\hline YS (MPa) & TS (MPa) & El (\%) \\
\hline 906 & 1214 & 14.5 \\
\hline
\end{tabular}

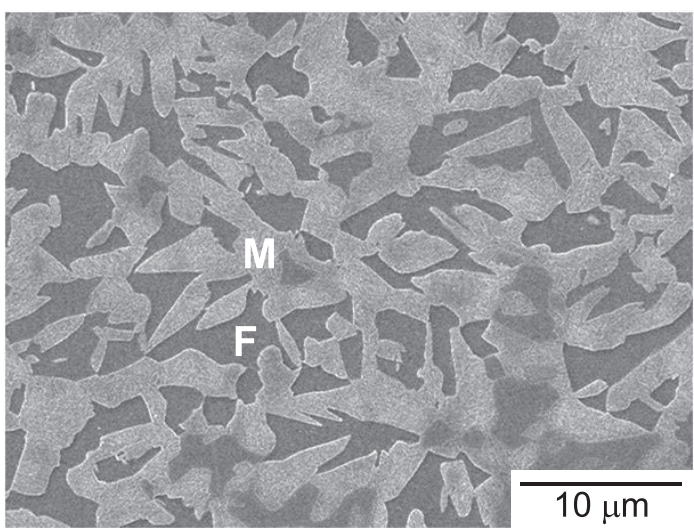

Fig. 1. SEM micrograph of steel studied (F: Ferrite, M: Martensite).

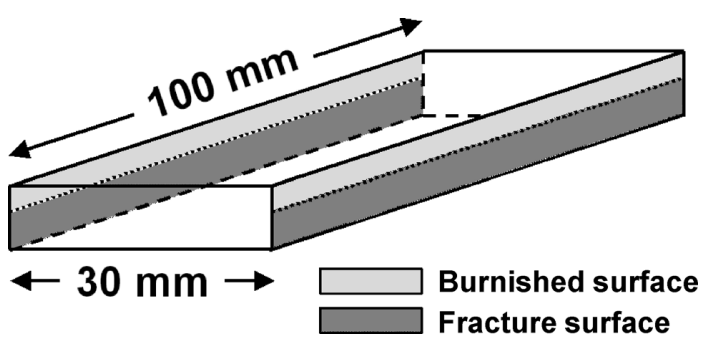

Fig. 2. Schematic illustration of as-sheared specimen.

martensite dual-phase steel sheet (thickness: $1.6 \mathrm{~mm}$ ). ${ }^{1,2)}$ The mechanical properties and SEM microstructure of the steel are shown in Table 1 and Fig. 1. The steel has the complex microstructure which contains approximately $40 \%$ of ferrite and $60 \%$ of martensite in volume fraction. The size of both grains is approximately $10 \mu \mathrm{m}$ or less. The steel sheet was sheared to dimensions of $100 \mathrm{~mm} \times 30 \mathrm{~mm}$, as shown in Fig. 2. The rolling direction was parallel to the longitudinal direction of the specimen. Two longitudinal edges were sheared so that the burnished surface and the fracture surface on both edges were at the same side. Specimens with the edges ground after shearing (hereafter referred to as "ground specimen") were also prepared.

Figure 3 shows a schematic illustration of the preparation procedure of U-bending specimens for the hydrogen embrittlement test. Specimens were bent perpendicular to the longitudinal direction with a bending radius $(R)$ of $5 \mathrm{~mm}$ or 10 $\mathrm{mm}$ into a U-shape. Two types of as-sheared specimens were prepared by bending so that the burnished surface (Fig. 4(a)) or the fracture surface (Fig. 4(b)) was the outer side of the specimen. Hereafter, the specimens shown in Figs. 4(a) and 4(b) are referred to as "burnished surface specimen" and "fracture surface specimen", respectively. After bending, a maximum surface stress of $900 \mathrm{MPa}$ was applied to the top of the specimen in the longitudinal direction by tightening its spring-back with a bolt. The surface stress at the top of the specimen was measured by means of X-ray diffractometer with the iso-inclination method. ${ }^{13)}$

The time to fracture of these specimens was investigated by immersing the specimens in a solution of hydrochloric

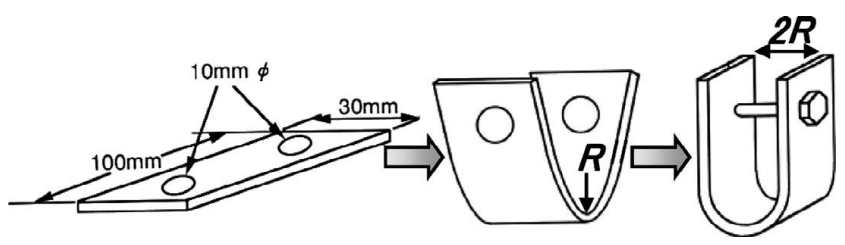

Fig. 3. Preparation procedure of specimen for hydrogen embrittlement test ( $R$ : bending radius).

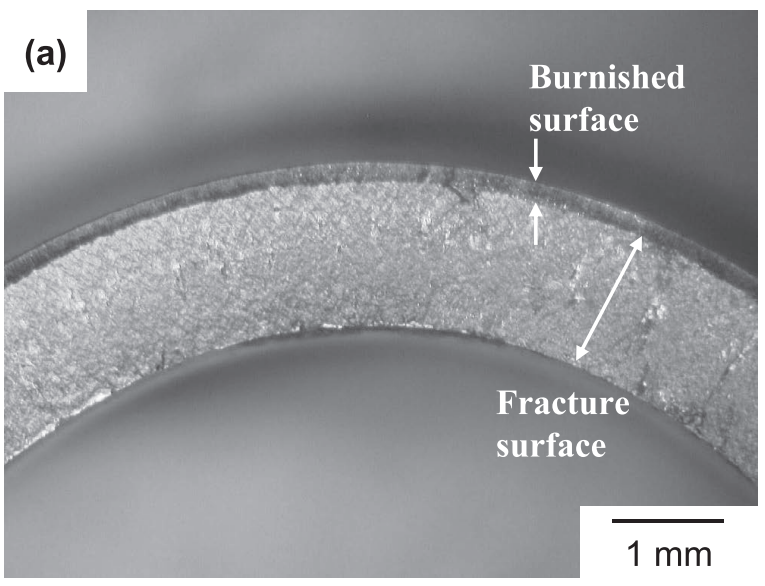

(b)

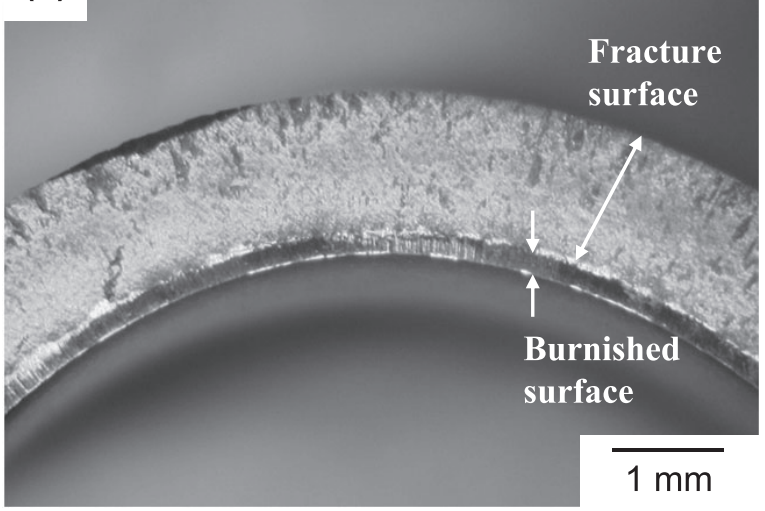

Fig. 4. Macroscopic photographs of specimens bent to bending radius $R=5 \mathrm{~mm}$; (a) burnished surface specimen and (b) fracture surface specimen.

acid $(\mathrm{HCl})$ with $\mathrm{pH} 1$ to 4 up to a maximum time of $96 \mathrm{~h}$. The reason for ending the test at $96 \mathrm{~h}$ is that there have been no specimens so far which fractured after $96 \mathrm{~h}$ in $200 \mathrm{~h}$ immersion tests. The amount of hydrogen that entered the steel when immersed in the $\mathrm{HCl}$ solutions was measured by thermal desorption analysis (TDA) using gas chromatography. A $5 \mathrm{~mm}$ width specimen for TDA was cut from the top of each bent specimen and it was kept in liquid nitrogen to prevent the emission of diffusible hydrogen. Before inserting the specimen into TDA device, it was polished in a dry condition followed by the ultrasonic cleaning. It took approximately 10 minutes after taking out the specimen from the liquid nitrogen container until TDA analysis of the specimen starts. A GC7000-T produced by J-SCIENCE LAB Co. Ltd. was used for the analysis. The heating rate was $200^{\circ} \mathrm{C} / \mathrm{h}$, and the sampling interval was $5 \mathrm{~min}$. In this study, the integration of the first evolution peak (below about $200^{\circ} \mathrm{C}$ ) was defined as the diffusible hydrogen content. 


\section{Results}

\subsection{Influence of Shearing on Hardness Near Edge}

Figure 5 shows SEM micrographs of the as-sheared edge (Fig. 5(a)) and the ground edge after shearing (Fig. 5(b)) at the ND-RD section. The ratio of burnished surface to the thickness was approximately $25 \%$. The burnished surface and the fracture surface generated by shearing were removed by grinding (Fig. 5(b)). Figure 6 shows the change in hardness on the ND-TD section of the as-sheared steel sheet with distance from the sheared edge. The hardness test was performed with a load of $20 \mathrm{~g}$ and a load time of $15 \mathrm{~s}$ using a micro Vickers hardness tester. Also, the data of bur-

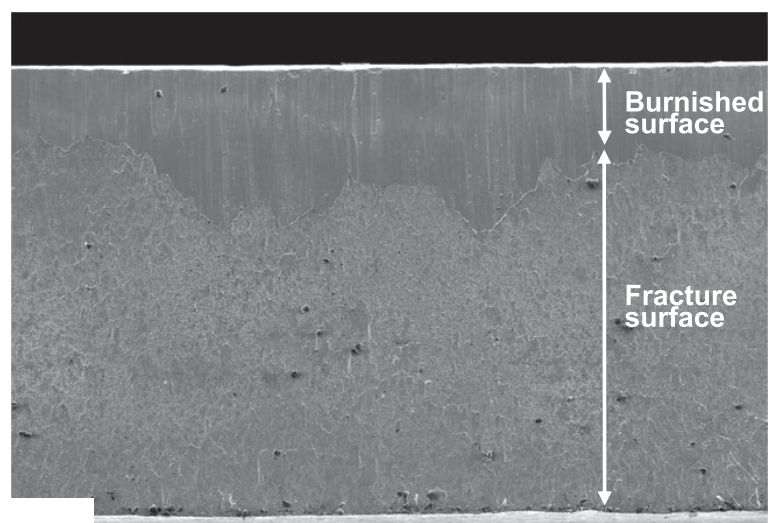

(a)

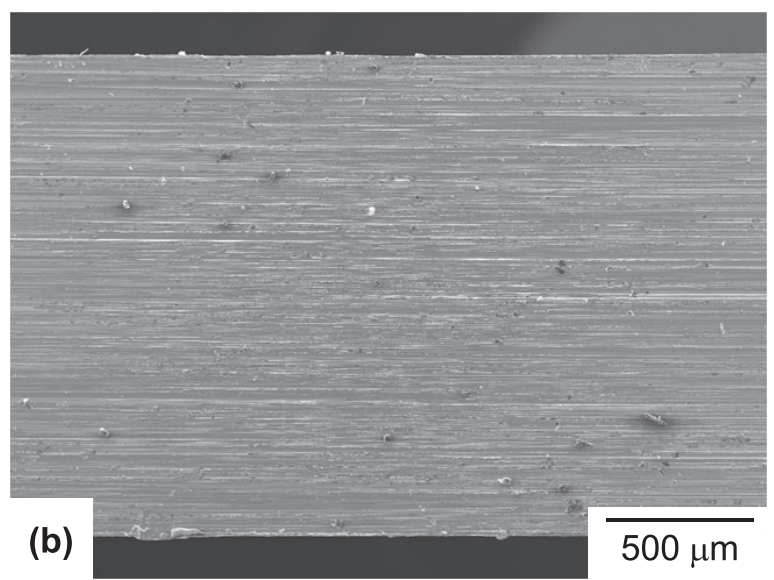

Fig. 5. SEM micrographs of steels at ND-RD section surface; (a) as-sheared surface and (b) ground surface after shearing.

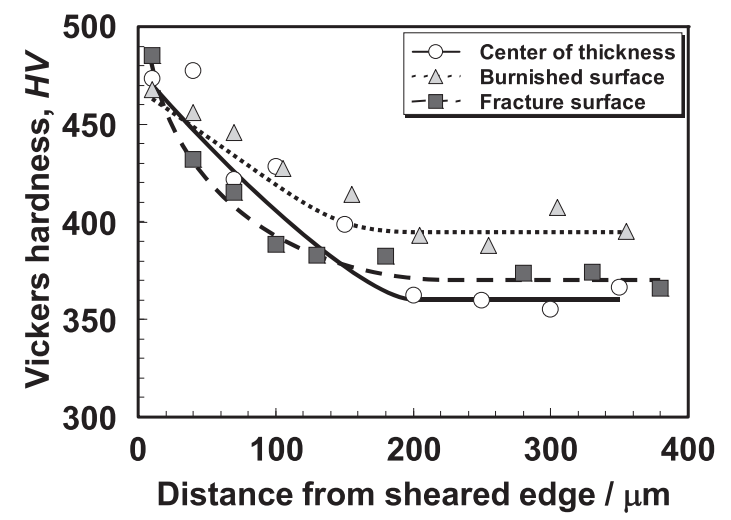

Fig. 6. Change in hardness of the as-sheared steel with distance from sheared edge. nished surface was measured at the part approximately 100 $\mu \mathrm{m}$ away from ND surface, and the date of fracture surface was measured at the part approximately $50 \mu \mathrm{m}$ away from another ND surface. Although a high hardness value of HV480 was measured near the sheared edge, the hardness decreased with the distance from the sheared edge and converged on a steady value of HV360-400 at positions around $200 \mu \mathrm{m}$ or more from the edge. Therefore, it is considered that the volume affected by shearing was approximately within $200 \mu \mathrm{m}$ from the sheared edge.

\subsection{Influence of Sheared Edge on Fracture Behavior}

Figure 7 shows the influence of the edge condition on the relationship between the applied stress and time to fracture of the bent specimens $(R=10 \mathrm{~mm})$ when immersed in the $\mathrm{pH} 1 \mathrm{HCl}$ solution. The ground specimens did not fracture at any applied stress. Thus, their fracture stress was estimated as over $900 \mathrm{MPa}$. On the other hand, the burnished surface specimen fractured at $900 \mathrm{MPa}$ and the fracture surface specimens fractured at $450 \mathrm{MPa}$ or more, of which fracture occurred from the edge. Therefore, the critical fracture stress decreased significantly in the as-sheared specimen in comparison with the ground specimen. These results were qualitatively in agreement with the results reported by Hayashi et al. in an investigation using the cathodic charge technique. ${ }^{6}$ Furthermore, the critical fracture stress in the fracture surface specimen decreased more drastically as compared with that in the burnished surface specimen.

Figure 8 shows the influence of the edge condition on

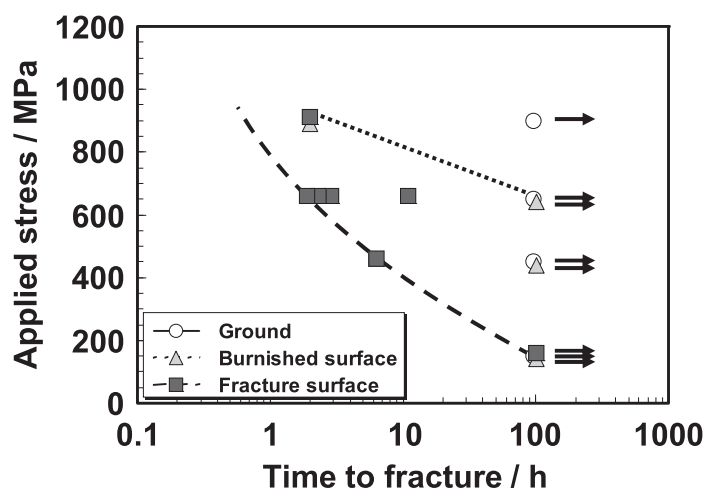

Fig. 7. Relationship between applied stress and time to fracture of bent steel $(R=10 \mathrm{~mm})$ when immersed in $\mathrm{pH} 1 \mathrm{HCl}$ solution.

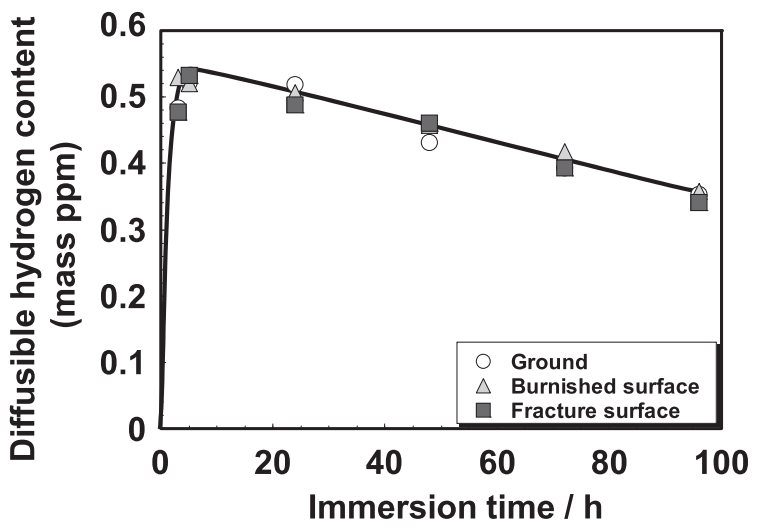

Fig. 8. Change in content of diffusible hydrogen entering specimen $(R=10 \mathrm{~mm})$ with immersion time in $\mathrm{pH} 1 \mathrm{HCl}$ solution. 

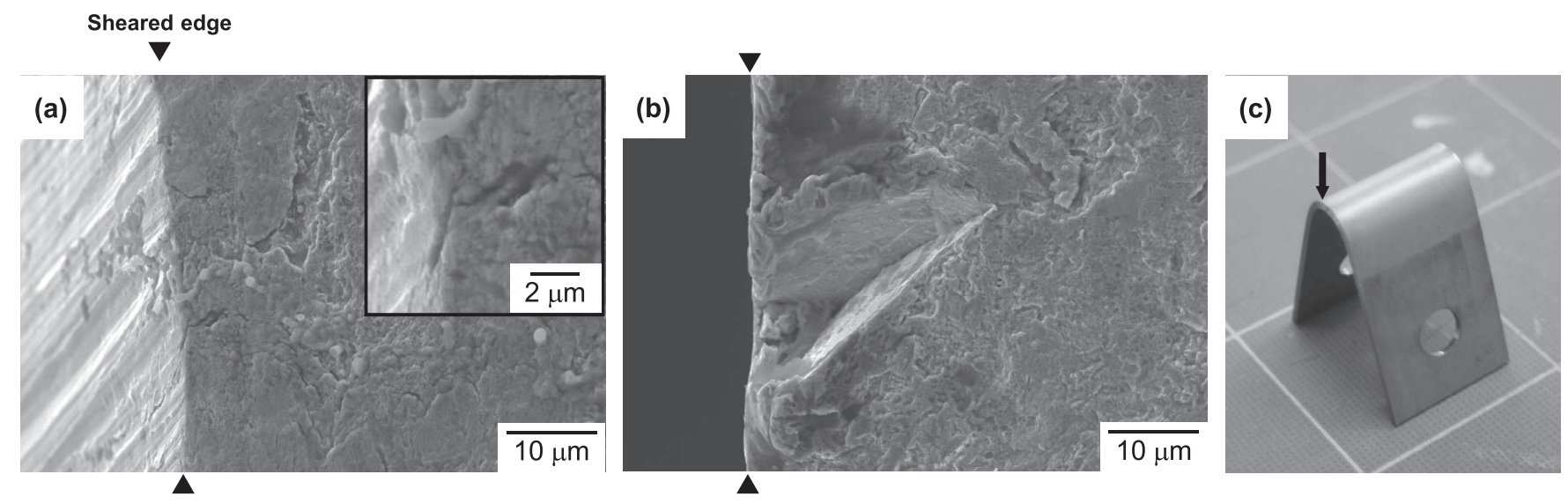

Fig. 9. SEM micrographs of top of bent specimens $(R=5 \mathrm{~mm})$; (a) burnished surface specimen, (b) fracture surface specimen, and (c) overview of specimen (arrow indicates observation direction).

the diffusible hydrogen content which entered the bent specimens $(R=10 \mathrm{~mm})$ when immersed in the $\mathrm{pH} 1 \mathrm{HCl}$ solution. The relationship between immersion time and diffusible hydrogen content was almost the same in each specimen. This result indicates the as-sheared specimens fractured at clearly lower stress even though almost the same quantity of diffusible hydrogen entered the as-sheared specimens as compared with that entered the ground specimens. After the diffusible hydrogen content reached its peak at $5 \mathrm{~h}$, it decreased with the immersion time. This is attributed to the fact that the average diffusible hydrogen content of the overall thickness measured by TDA decreased due to dissolution of the surface of the specimen by the long-term immersion, where larger strain was induced. ${ }^{14)}$ The influence of dissolution of the specimens by immersion in the $\mathrm{HCl}$ solution on the evaluated results is discussed in section 4.1.

SEM photographs taken from around the top of the specimen bent with $R=10 \mathrm{~mm}$ after shearing are shown in Fig. 9. Although no cracks were observed in any specimen before bending, cracks were observed at the edge of the assheared specimen after bending. No cracks were observed in the ground specimen after bending. The crack observed in the burnished surface specimen (Fig. 9(a)) was small, being about $3 \mu \mathrm{m}$. However, in comparison with the burnished surface specimen, the crack observed in the fracture surface specimen (Fig. 9(b)) was about $30 \mu \mathrm{m}$, and it is opened widely in the thickness direction. The reason for generation of large cracks in fracture surface specimen was considered that the stress concentration easily occurred when bending; it is due to formation of ripped morphology in the thickness direction at the edge of fracture specimen by shearing. Figure 10 shows photographs which compare the crack at the top of the fracture surface specimen $(R=10 \mathrm{~mm})$ before and after immersion in the $\mathrm{pH} 1 \mathrm{HCl}$ solution. Many cracks with sizes of several dozen to 100 micrometers were observed before immersion (Fig. 10(a)). The crack indicated by the arrow, which was generated by bending, propagated until it penetrated in the thickness direction when the specimen was immersed in the $\mathrm{pH} 1 \mathrm{HCl}$ solution for $1.5 \mathrm{~h}$ (Fig. 10(b)). According to these results, the fact that the critical fracture stress in the as-sheared specimens decreased drastically in comparison with the ground specimen is attributed to the crack at the edge which was generated by bending,

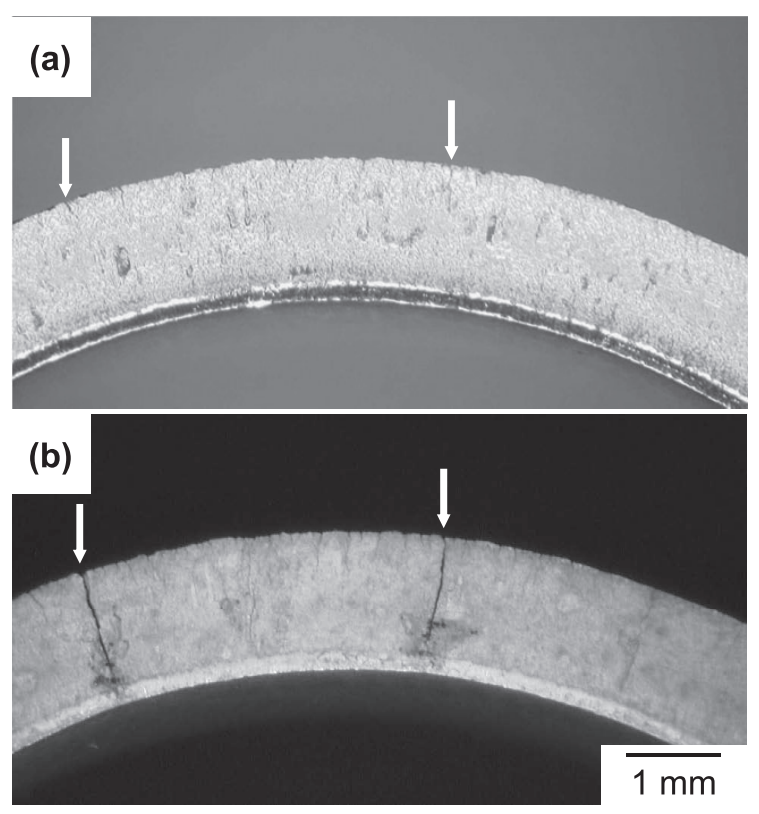

Fig. 10. Macroscopic photographs of fracture surface specimen $(R=$ $10 \mathrm{~mm}$ ) before and after immersion in $\mathrm{pH} 1 \mathrm{HCl}$ solution for $1.5 \mathrm{~h}$; (a) before immersion and (b) after immersion for $1.5 \mathrm{~h}$. Arrows show the same cracks before and after immersion.

and the difference in the critical fracture stress between the burnished surface specimen and the fracture surface specimen is considered to be due to the difference in the length or propagation behavior of the crack.

\subsection{Influence of Diffusible Hydrogen Content on Frac- ture Behavior}

Figure 11 shows the relationship between applied stress and time to fracture of burnished surface specimens (Fig. 11(a)) and fracture surface specimens (Fig. 11(b)) respectively, when specimens were immersed in $\mathrm{pH} 1,3$ and $4 \mathrm{HCl}$ solutions. Although the time to fracture under $\mathrm{pH} 3$ was slightly longer than that under $\mathrm{pH} 1$, the critical fracture stress under $\mathrm{pH} 3$ was the same as that under $\mathrm{pH} 1$. That is, the critical fracture stress of burnished surface specimen and fracture surface specimen was $650 \mathrm{MPa}$ and $200 \mathrm{MPa}$, respectively, and it was independent of the $\mathrm{pH}$ of the solution. In contrast, when immersed in the $\mathrm{pH} 4 \mathrm{HCl}$ solution, 
(a)

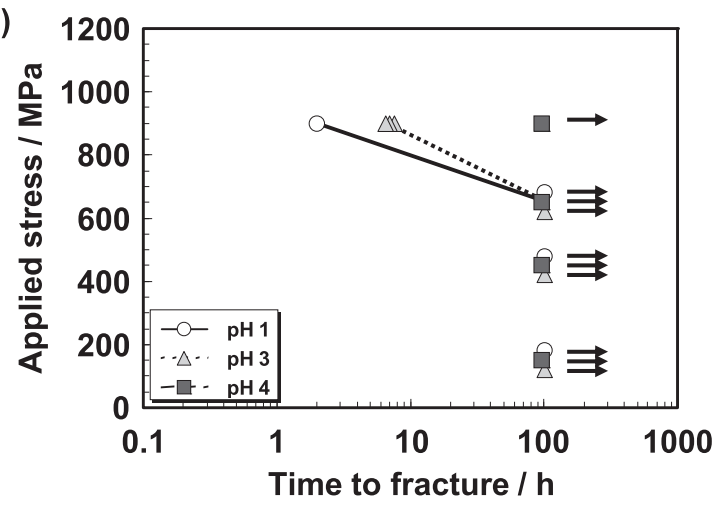

(b)

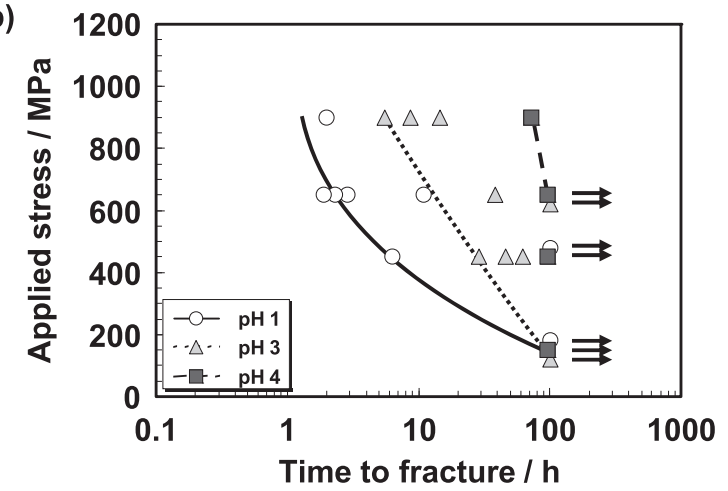

Fig. 11. Stress-time to fracture curves of specimen $(R=10 \mathrm{~mm})$ when immersed in $\mathrm{HCl}$ solutions with various $\mathrm{pH}$ levels; (a) burnished surface specimen and (b) fracture surface specimen.

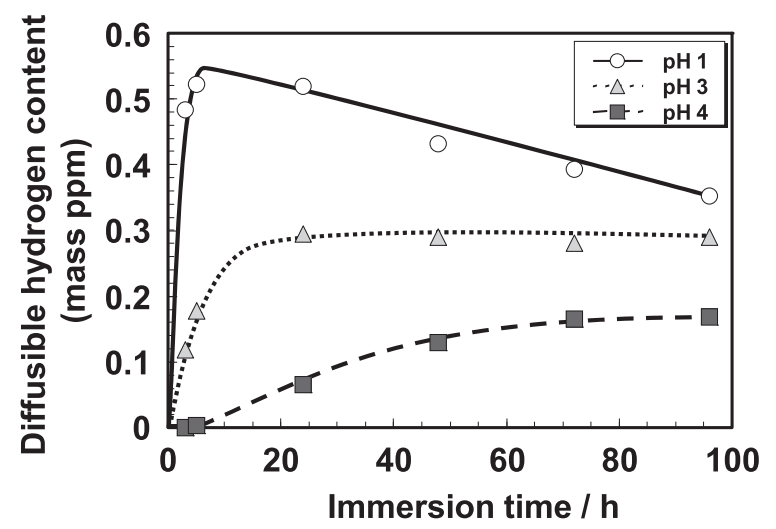

Fig. 12. Change in content of diffusible hydrogen entering the ground specimen $(R=10 \mathrm{~mm})$ with immersion time in $\mathrm{HCl}$ solutions with various $\mathrm{pH}$ levels.

the burnished surface specimen did not fracture at $900 \mathrm{MPa}$, and the critical fracture stress in the fracture surface specimen increased from $200 \mathrm{MPa}$ to $650 \mathrm{MPa}$. Figure 12 shows the change in the content of diffusible hydrogen entering the ground specimen $(R=10 \mathrm{~mm})$ with immersion time in $\mathrm{pH}$ 1-4 $\mathrm{HCl}$ solutions. The lower $\mathrm{pH}$ showed higher diffusible hydrogen content than the higher $\mathrm{pH}$ in any immersion time. The maximum values of diffusible hydrogen under the $\mathrm{pH}$ 1,3 and 4 solutions were $0.54 \mathrm{ppm}, 0.30 \mathrm{ppm}$ and $0.17 \mathrm{ppm}$, respectively. Therefore, it is considered that the increase of the critical fracture stress in $\mathrm{pH} 4 \mathrm{HCl}$ solution was due to a decrease in the diffusible hydrogen content entering the steel.
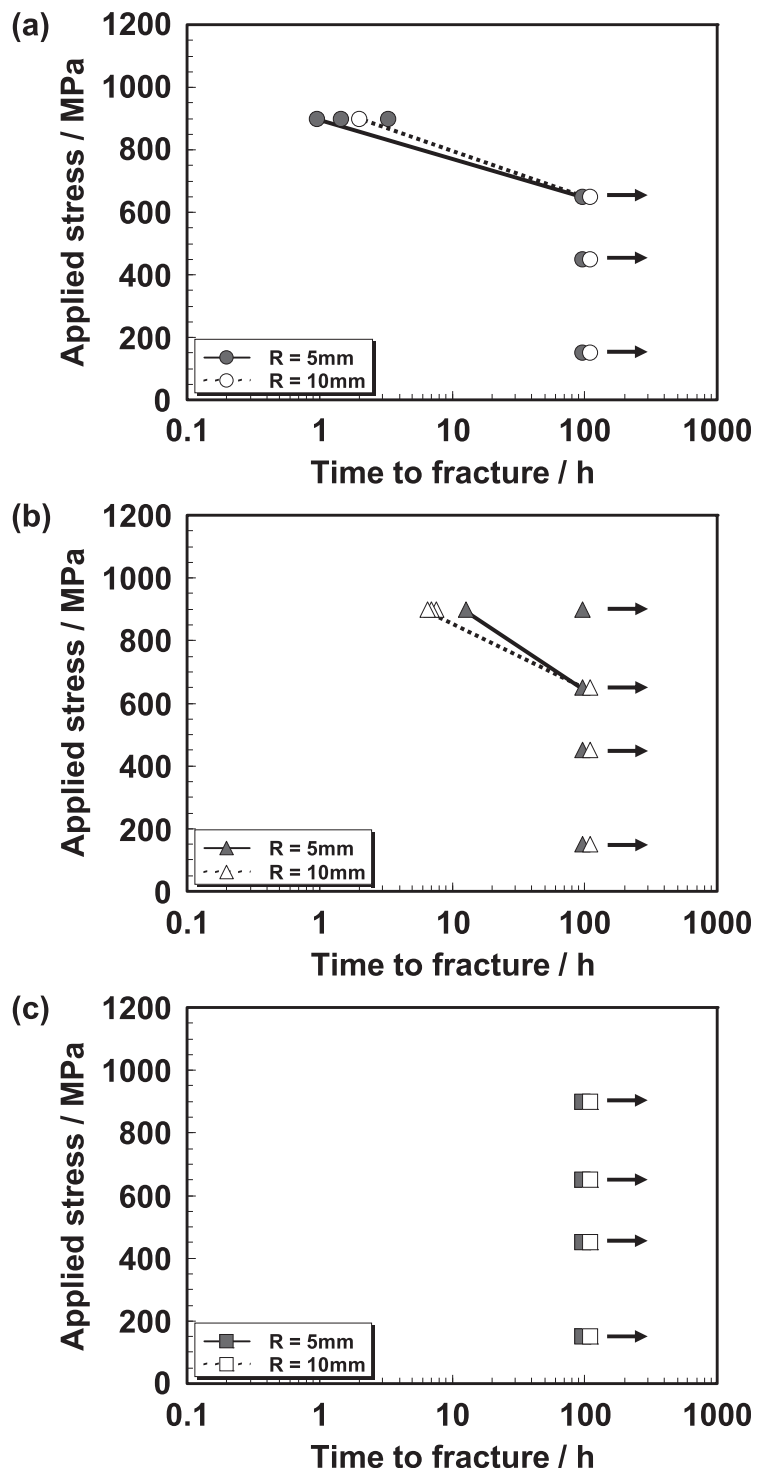

Fig. 13. Comparison of time to fracture curves of burnished surface specimens with bending radii of $5 \mathrm{~mm}$ and $10 \mathrm{~mm}$ when immersed in $\mathrm{HCl}$ solutions with various $\mathrm{pH}$ levels; (a) $\mathrm{pH} 1$, (b) $\mathrm{pH} 3$ and (c) $\mathrm{pH} 4$.

\subsection{Influence of Bending Radius on Fracture Behavior}

The stress-time to fracture curves of the burnished surface specimen and the fracture surface specimen $(R=5 \mathrm{~mm})$ when immersed in $\mathrm{pH} 1-4 \mathrm{HCl}$ solutions are shown in Figs. 13 and 14, together with the results of the $R=10 \mathrm{~mm} \mathrm{spec-}$ imen which were shown in Fig. 7. The critical fracture stress in the burnished surface specimen did not depend on the bending radius, and was unchanged at $650 \mathrm{MPa}$ in the $\mathrm{pH} 1$ and 3 solutions (Figs. 13(a) and 13(b)) and at $900 \mathrm{MPa}$ in the $\mathrm{pH} 4$ solution (Fig. 13(c)).

However, the fracture surface specimen $(R=5 \mathrm{~mm})$ fractured at $150 \mathrm{MPa}$ in both the $\mathrm{pH} 1$ and 3 solutions (Figs. 14(a) and 14(b)), but did not fracture at $R=10 \mathrm{~mm}$. In other words, the critical fracture stress decreased when the bending radius was decreased. Meanwhile, the time to fracture when the specimens with both $R=5 \mathrm{~mm}$ and $R=10 \mathrm{~mm}$ fractured was almost the same under all pH levels in both the burnished surface specimen and the fracture surface specimen, indicating that the influence of the bending radius on the time to fracture was small. 
(a)

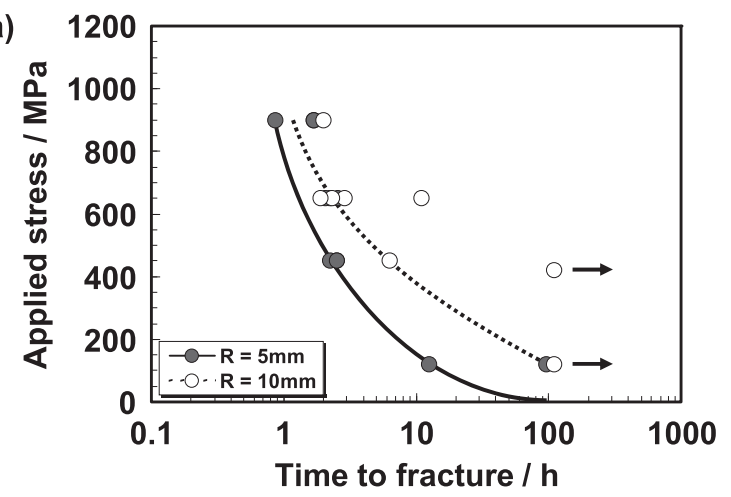

(b)

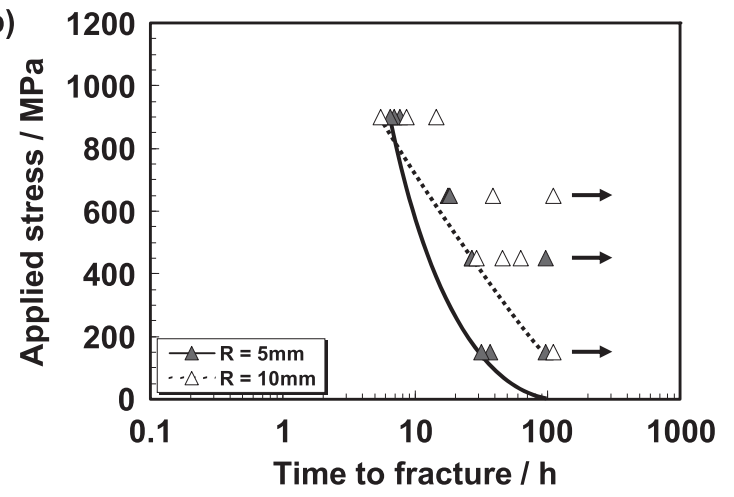

(c)

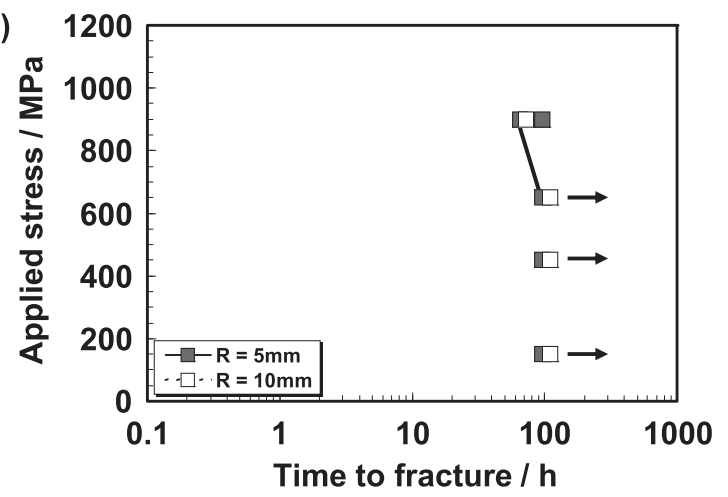

Fig. 14. Comparison of time to fracture curves of fracture surface specimens with bending radii of $5 \mathrm{~mm}$ and $10 \mathrm{~mm}$ when immersed in $\mathrm{HCl}$ solutions with various $\mathrm{pH}$ levels; (a) $\mathrm{pH}$ 1, (b) $\mathrm{pH} 3$ and (c) $\mathrm{pH} 4$.

\section{Discussion}

In this chapter, in order to clarify the reason why the critical fracture stress was different between the burnished surface specimen and the fracture surface specimen first, the influence of dissolution of the specimen during immersion in the $\mathrm{HCl}$ solution on the evaluated result is investigated, and then the deterioration mechanism of the critical fracture stress in as-sheared specimens is discussed from the point of view of local hydrogen accumulation near the sheared edge and material damage near the sheared edge by bending.

\subsection{Influence of Dissolution of Specimen on Critical Fracture Stress}

Figure 15 shows the weight loss (Fig. 15(a)) and the amount of dissolution from the edge in the width direction of the specimen (Fig. 15(b)) when ground specimens $(R=$ $10 \mathrm{~mm}$ ) were immersed in $\mathrm{pH} 1-4 \mathrm{HCl}$ solutions. As the weight loss when specimens were immersed in the $\mathrm{pH} 3$ and $4 \mathrm{HCl}$ solutions was below $2 \%$, dissolution was essentially (a)

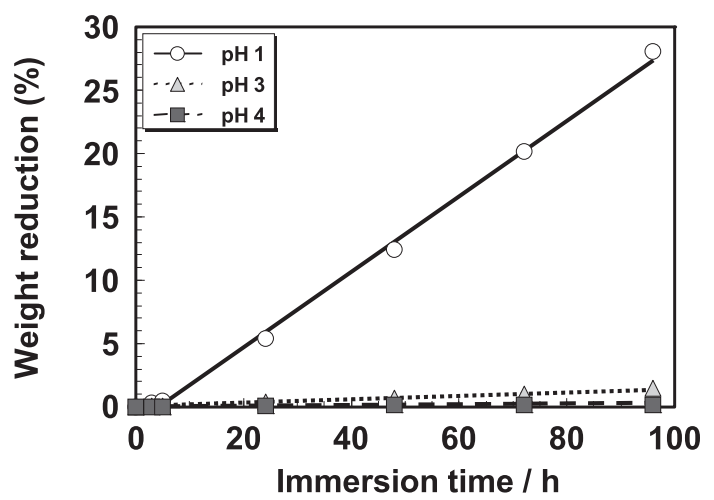

(b)

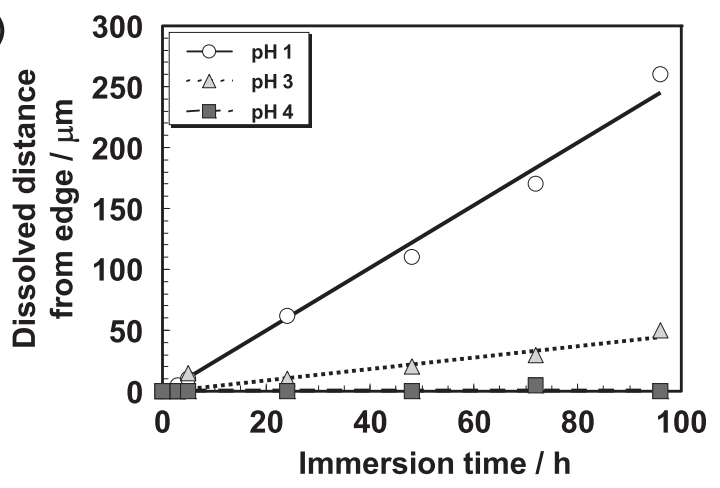

Fig. 15. Change in (a) weight reduction and (b) dissolved distance from edge of ground specimens $(R=10 \mathrm{~mm})$ when immersed in $\mathrm{HCl}$ solutions with various $\mathrm{pH}$ levels.

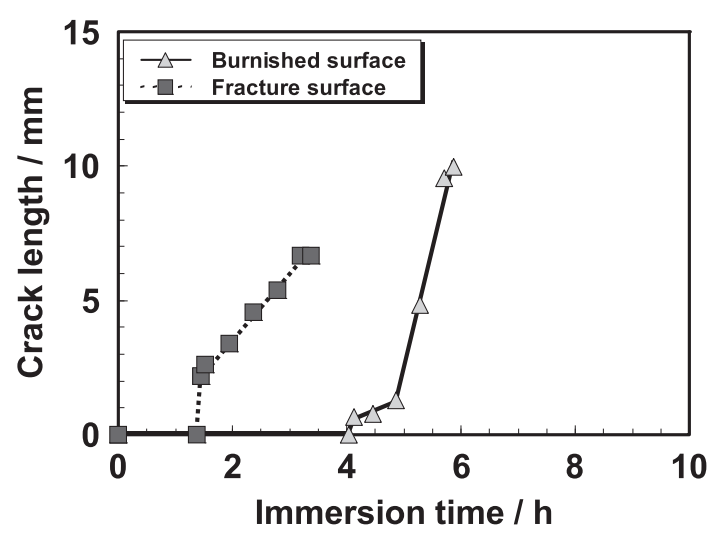

Fig. 16. Change in crack length of specimens $(R=10 \mathrm{~mm})$ with immersion time in $\mathrm{pH} 1 \mathrm{HCl}$ solution.

insignificant. However, when immersed in the $\mathrm{pH} 1 \mathrm{HCl}$ solution, approximately $6 \%$ of the specimen was dissolved in $24 \mathrm{~h}$, and approximately $28 \%$ was dissolved in $96 \mathrm{~h}$. In addition, the dissolution of the specimen in the width direction from the edge in the $\mathrm{pH} 1 \mathrm{HCl}$ solution was about 60 $\mu \mathrm{m}$ in $24 \mathrm{~h}$ and about $260 \mu \mathrm{m}$ in $96 \mathrm{~h}$. Almost the same results were obtained with the burnished surface specimen and the fracture surface specimen.

Figure 16 shows the change in crack length with immersion time in the $\mathrm{pH} 1 \mathrm{HCl}$ solution for the burnished surface specimen and fracture surface specimen with $R=10 \mathrm{~mm}$ when surface stress of $900 \mathrm{MPa}$ was applied. The crack introduced by bending propagated over $0.5 \mathrm{~mm}$ in $4 \mathrm{~h}$ in the burnished surface specimen and in $1.5 \mathrm{~h}$ in the fracture surface specimen. The crack observed in the fracture surface specimen propagated at a constant rate of about $2.4 \mathrm{~mm} / \mathrm{h}$. In contrast, although the crack observed in the burnished 
surface specimen propagated slowly at approximately 0.8 $\mathrm{mm} / \mathrm{h}$ until about $1 \mathrm{~h}$ after crack initiation, it propagated rapidly at $9.2 \mathrm{~mm} / \mathrm{h}$ after $1 \mathrm{~h}$.

As shown in Fig. 7, the time to fracture in the burnished surface specimen and the fracture surface specimen was a maximum of $10 \mathrm{~h}$ in the $\mathrm{pH} 1 \mathrm{HCl}$ solution. Based on the fact that the dissolution distance from the edge was about 30 $\mu \mathrm{m}$ after immersion for $10 \mathrm{~h}$ (Fig, 15(b)), the hardened layer which was generated by shearing sufficiently remained. Furthermore, the crack growth rate in the burnished surface specimen and the fracture surface specimen was two or three orders larger than the dissolution rate of the specimen, as shown in Fig. 16. That is, it is obvious that the crack at the edge propagated rapidly as a result of immersion in the $\mathrm{HCl}$ solution rather than dissolution of the volume affected by shearing. Consequently, it is considered that the influence of dissolution of the specimen by immersion in the $\mathrm{HCl}$ solution on the critical fracture stress was negligible in the $\mathrm{pH} 1 \mathrm{HCl}$ solution, as well as in the $\mathrm{pH} 3$ and 4 solutions.

\subsection{Influence of Local Hydrogen Accumulation Near Sheared Edge}

Hydrogen is usually understood to be trapped by material defects such as dislocations and point defects, ${ }^{15,16)}$ and diffusible hydrogen entering steel increases with increasing strain and/or material defects. ${ }^{14,17,18)}$ For instance, Toji et $a l .{ }^{14)}$ investigated the influence of rolling strain on the diffusible hydrogen content entering $1180 \mathrm{MPa}$ grade DP steel sheets, which is the same steel as that used in this study, and reported that the diffusible hydrogen content entering the steel sheets increased with increasing rolling strain. Since shearing is a process which involves large plastic deformation, large plastic strain is also introduced at the sheared edge compared with the part which is not affected by shearing deformation. Therefore, the diffusible hydrogen content at the sheared edge was investigated.

Steel sheets without deformation or with cold-rolling with $15 \%$ reduction were used in this investigation. This is because it is difficult to extract a sample which only includes the edge part from the top of bent specimens. According to the following equations, the equivalent strain induced by cold-rolling with $15 \%$ reduction is almost equal to that at the top of the bent specimen $(R=5 \mathrm{~mm})$.

$$
\begin{gathered}
\varepsilon_{e q}=\frac{2}{\sqrt{3}} \ln \left(\frac{t_{0}}{t}\right) . \\
\varepsilon_{e q}=\frac{t_{0}}{2 R+t_{0}} \times \frac{2}{\sqrt{3}}
\end{gathered}
$$

where $\varepsilon_{e q}$ is the equivalent strain, $t_{0}$ is the thickness of the prepared steel sheet, $t$ is the thickness after cold-rolling and $R$ is the bending radius.

From these steel sheets, $60 \mathrm{~mm}$ length $\times 1 \mathrm{~mm}$ width specimen with the longitudinal direction parallel to the rolling direction was cut from the sheared edge at $1 \mathrm{~mm}$ intervals by using abrasive cutting. The reason for using abrasive cutting was to avoid the generation of new sheared edges except for the original sheared edge.

Quantitative analysis of diffusible hydrogen entering the specimen was performed after immersion in a $0.01 \%$ ammonium thiocyanate $\left(\mathrm{NH}_{4} \mathrm{SCN}\right)$ solution for a maximum of 96 h. The $\mathrm{NH}_{4} \mathrm{SCN}$ solution is commonly used for hydrogen charging in the FIP test. ${ }^{20)}$ Takagi et al. reported that the diffusible hydrogen content entering steel can be controlled by changing the amount of $\mathrm{NH}_{4} \mathrm{SCN}$ in the solution with hardly any dissolution. ${ }^{21,22)}$ The $0.01 \% \mathrm{NH}_{4} \mathrm{SCN}$ solution used in this study introduces almost the same diffusible hydrogen content as the $\mathrm{pH} 3 \mathrm{HCl}$ solution introduced into the bent steel specimens. Additionally, 6 specimens with a $60 \mathrm{~mm}$ length $\times 1 \mathrm{~mm}$ width, which were immersed at the same time, were analyzed at once by TDA to enhance measurement accuracy.

Figure 17 shows the hydrogen evolution curves of the assheared specimen when immersed in the $0.01 \% \mathrm{NH}_{4} \mathrm{SCN}$ solution for $24 \mathrm{~h}$. An obvious hydrogen evolution peak was detected below $200^{\circ} \mathrm{C}$ in the part from the edge to $1 \mathrm{~mm}$ of the specimen. However, no hydrogen evolution peak was detected at any temperatures at the part $1 \mathrm{~mm}$ or more from

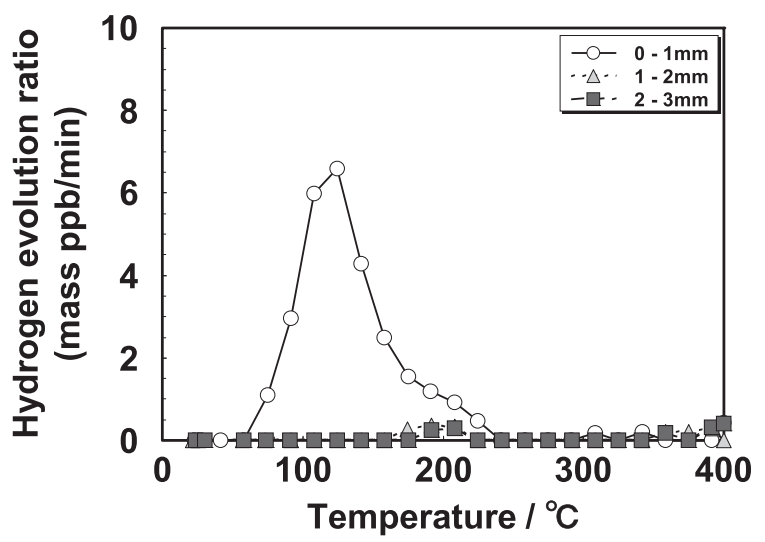

Fig. 17. Influence of sampling position on hydrogen evolution behavior of steel immersed for $24 \mathrm{~h}$ in $0.01 \% \mathrm{NH}_{4} \mathrm{SCN}$ solution.

(a)

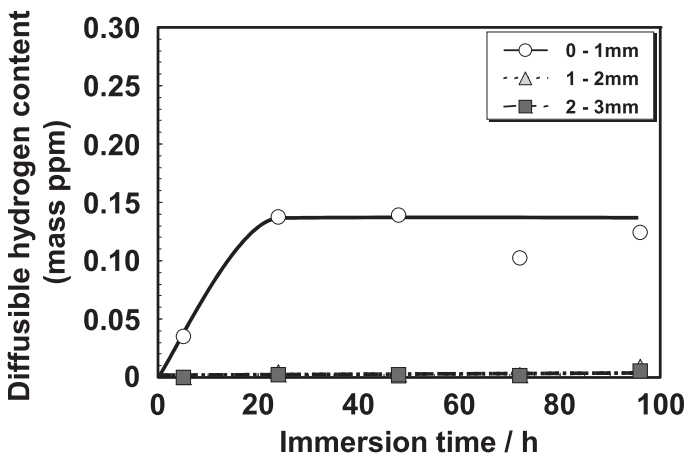

(b)

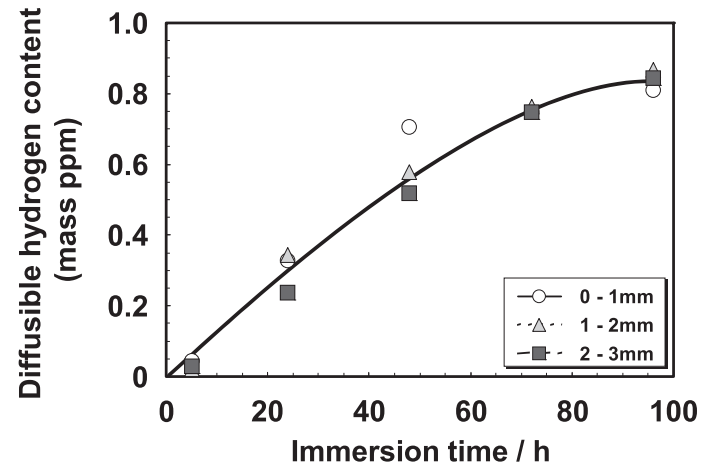

Fig. 18. Change in content of diffusible hydrogen entering specimens with immersion time in $0.01 \% \mathrm{NH}_{4} \mathrm{SCN}$ solution; (a) as-sheared and (b) cold-rolled with $15 \%$ reduction. 
the edge. These results indicated that the diffusible hydrogen locally accumulated near the sheared edge in the assheared steel sheet.

The changes in diffusible hydrogen content with immersion time in the specimen with and without cold-rolling with $15 \%$ reduction are shown in Fig. 18. In the specimen without cold rolling (Fig. 18(a)), the diffusible hydrogen at the part from the edge to $1 \mathrm{~mm}$ became constant at approximately $0.14 \mathrm{ppm}$ after immersion for $24 \mathrm{~h}$, and was higher than that of the part $1 \mathrm{~mm}$ or more away from the edge. On the other hand, in the specimen which was cold-rolled with $15 \%$ reduction (Fig. 18(b)), no difference in the diffusible hydrogen content was observed between the specimen at the part from the edge to $1 \mathrm{~mm}$ and the part $1 \mathrm{~mm}$ or more from the edge, and the diffusible hydrogen content increased with increasing immersion time. Although the hardened layer which was generated by shearing remained up to approximately $72 \mathrm{~h}$ immersion as shown in Fig. 15, no additional increment of entered diffusible hydrogen by shearing strain was observed at the part from the edge to $1 \mathrm{~mm}$ in the specimen which was cold-rolled with $15 \%$ reduction. It is considered that the contribution of the strain introduced by shearing at the edge became relatively smaller by strain of $15 \%$ cold-rolling, although the reason for this phenomenon did not explicit enough in the study. On the other hand, the critical fracture stress of burnished surface specimen and fracture surface specimen was clearly different as shown in Figs. 13 and 14, though both the specimens have the same sheared edges. Consequently, even if the local hydrogen accumulation near sheared edge was remarkable or not, it is considered that the critical fracture stress was strongly dom-

(a)

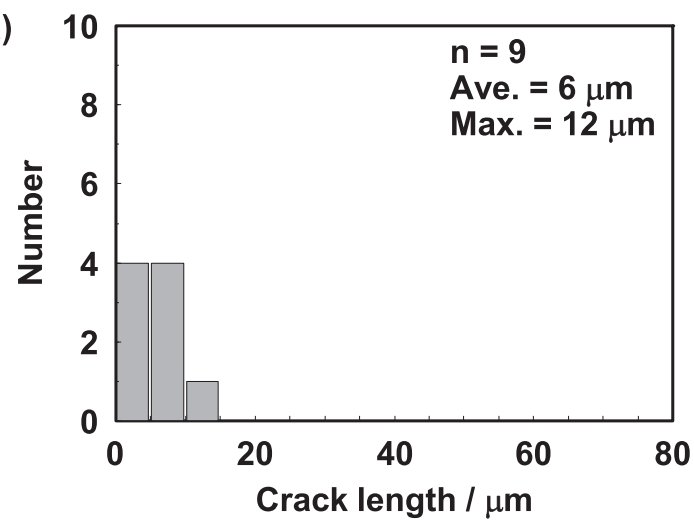

(c)

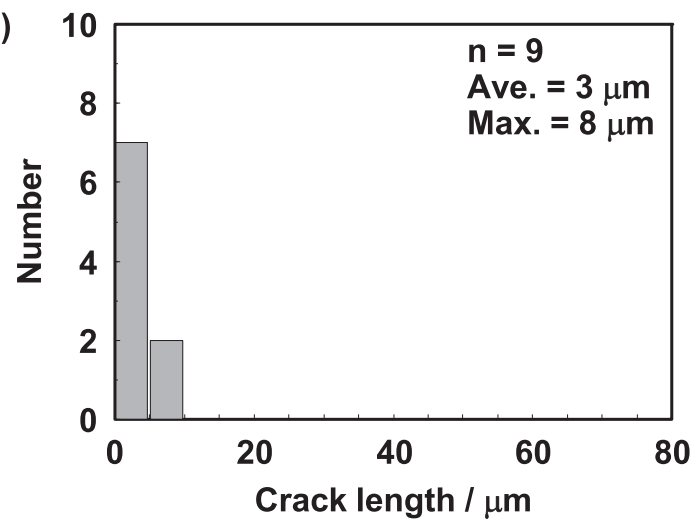

inated by microcracks which were introduced by bending as shown in Fig. 9.

\subsection{Influence of Crack Length on Fracture Stress}

Figure 19 shows the histograms of the crack length on the sheared edges of the burnished surface specimens and the fracture surface specimens bent with bending radii of 5 $\mathrm{mm}$ and $10 \mathrm{~mm}$. The cracks in the range of $\pm 5 \mathrm{~mm}$ from the center on the top of the bent specimen were measured, and the crack length was defined as the linear distance between the crack opening area at the edge and the crack tip. The number, average crack length and maximum crack length of the cracks showed little change in the burnished surface specimen when the bending radius was reduced from $R=10$ mm (Fig. 19(a)) to $5 \mathrm{~mm}$ (Fig. 19(c)). On the other hand, in the fracture surface specimen, cracks were observed at 5 places at $R=10 \mathrm{~mm}$ (Fig. 19(b)), but this number increased eightfold by bending at $R=5 \mathrm{~mm}$ (Fig. 19(d)), which introduced larger strain than $R=10 \mathrm{~mm}$. Furthermore, at $R=5$ $\mathrm{mm}$, the average crack length and the maximum crack length were $30 \mu \mathrm{m}$ and $78 \mu \mathrm{m}$, respectively. Therefore, in the fracture surface specimens, cracks clearly increased in both number and size as the bending radius decreased. When the burnished surface specimen and fracture surface specimen were compared at $R=5 \mathrm{~mm}$, the critical fracture stress in the fracture surface specimen was lower than that in the burnished surface specimen (Fig. 7), even though the number of cracks in the burnished surface specimen was larger than that in the fracture surface specimen. Although the influence of the number of cracks on the critical fracture stress has not been clarified in this study, it is considered
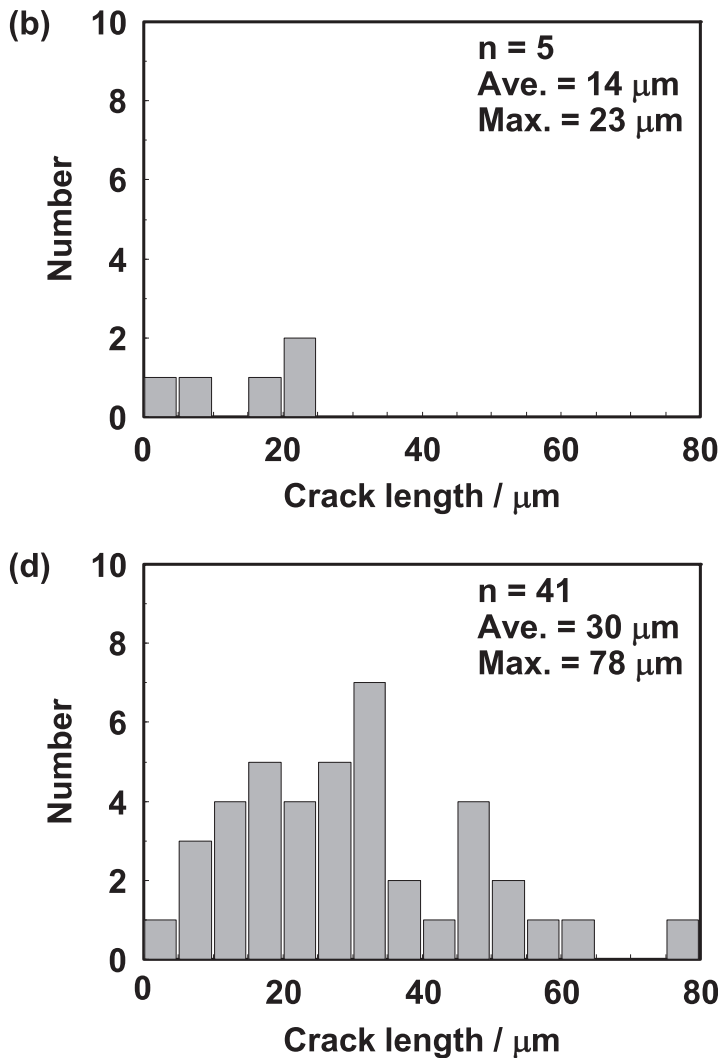

Fig. 19. Histogram of crack length in sheared edges of bent specimens; (a) burnished surface specimen $(R=10 \mathrm{~mm}),(\mathrm{b})$ fracture surface specimen $(R=10 \mathrm{~mm})$, (c) burnished surface specimen $(R=5 \mathrm{~mm})$ and $(\mathrm{d})$ fracture surface specimen $(R=5 \mathrm{~mm})$. 


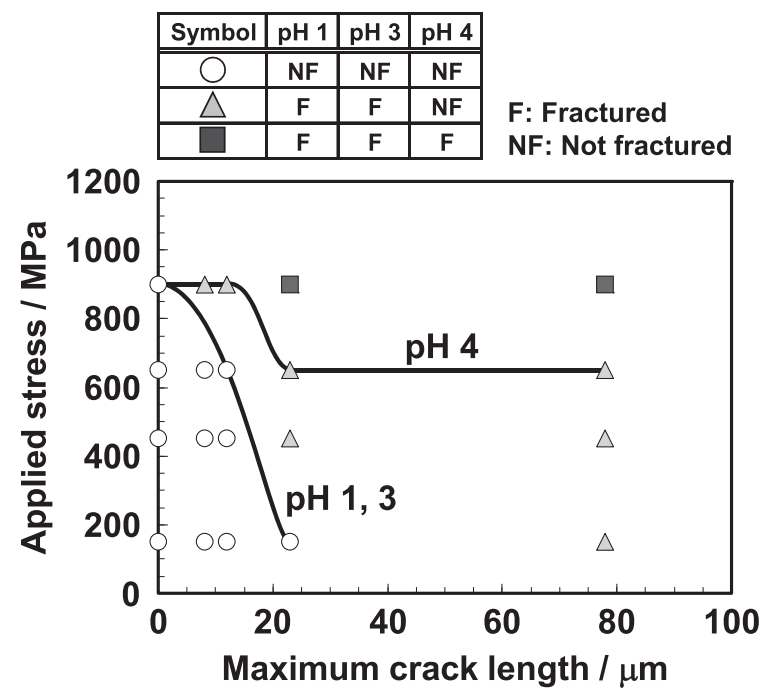

Fig. 20. Influence of maximum crack length on critical fracture stress of specimens when immersed in $\mathrm{HCl}$ solutions with various $\mathrm{pH}$ levels.

that the critical fracture stress was strongly influenced by the crack length rather than by the number of cracks.

The $\mathrm{HCl}$ immersion test results of the burnished surface specimen and fracture surface specimen were summarized by applied stress and the maximum crack length, as shown in Fig. 20. The lines in the figure indicate the maximum stress at which fracture did not occur; that is, fracture did not occur on the low stress side of this line. The critical fracture stress decreased at the maximum crack length of $8 \mu \mathrm{m}$ in the $\mathrm{pH} 1$ and $3 \mathrm{HCl}$ solutions, and it significantly decreased to $150 \mathrm{MPa}$ or less when the maximum crack length was more than $23 \mu \mathrm{m}$. Although the critical fracture stress in the $\mathrm{pH}$ $4 \mathrm{HCl}$ solution did not decrease until the maximum crack length of $12 \mu \mathrm{m}$, it decreased to $650 \mathrm{MPa}$ and became constant at $23 \mu \mathrm{m}$ or more. Therefore, there is a tendency for the critical fracture stress to decrease with increasing the maximum crack length, and it is considered that the decrement of the critical fracture stress and the dependence of the critical fracture stress on the maximum crack length were strongly influenced by the diffusible hydrogen content.

Generally, the relationship between crack length and critical fracture stress can be denoted by the following equation, which uses the stress intensity factor $K$.

$$
K=\sigma \sqrt{\pi a}
$$

where $K$ is the stress intensity factor, $\sigma$ is the applied stress, and $a$ is the crack length. In addition, it has been reported that the threshold stress intensity factor decreased when diffusible hydrogen entered steel. ${ }^{23)}$ When the threshold stress intensity factor at each diffusible hydrogen content was defined as $K_{H}$, the fracture condition was described as $K>$ $K_{H}$.

The relationship among crack length, applied stress and occurrence of fracture in Fig. 20 was rearranged by the diffusible hydrogen content and stress intensity factor, as shown in Fig. 21. The line in the figure indicates the minimum stress intensity factor at which fracture occurred. The diffusible hydrogen content on the horizontal axis is the maximum diffusible hydrogen content when the specimen is immersed in $\mathrm{HCl}$ solutions of each $\mathrm{pH}$ level, as shown in

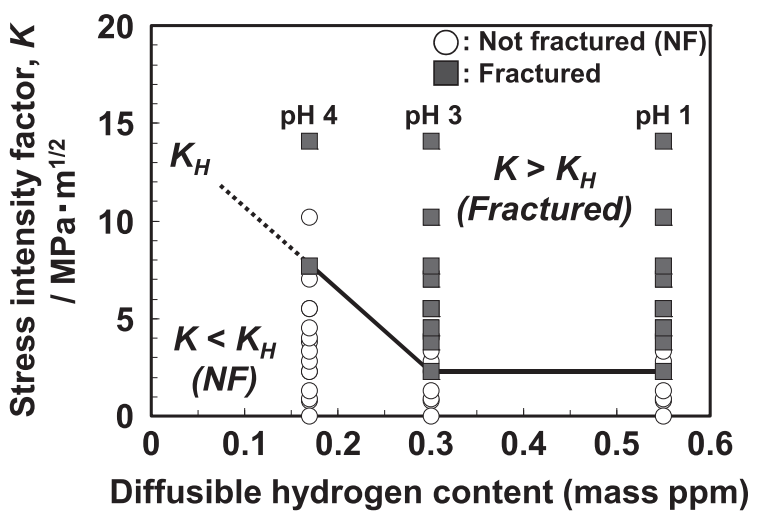

Fig. 21. Dependence of hydrogen cracking on stress intensity factor $K$ and diffusible hydrogen content in steel studied.

Fig. 12. $K_{H}$ greatly decreased to $2.3 \mathrm{MPa} \cdot \mathrm{m}^{1 / 2}$ when the amount of diffusible hydrogen increased to $0.30 \mathrm{ppm}(\mathrm{pH} 3$ $\mathrm{HCl}$ solution) from $0.17 \mathrm{ppm}(\mathrm{pH} 4 \mathrm{HCl}$ solution), and it became constant at diffusible hydrogen levels over 0.30 $\mathrm{ppm}$. Accordingly, the reason why the fracture stress in the pH 1 and $3 \mathrm{HCl}$ solutions significantly decreased in comparison with that in the $\mathrm{pH} 4 \mathrm{HCl}$ solution was considered to be because $K>K_{H}$ was satisfied at a relatively lower stress intensity factor due to the large decrement of $K_{H}$ resulting from the increment of the diffusible hydrogen content.

Wriedt and Oriani reported that the hydrogen content entering a material increased with the increment of tensile elastic stress. ${ }^{24)}$ When hydrostatic pressure affects a stress concentration region such as a notch or crack, it is considered that fracture is accelerated by accumulation of hydrogen at the stress concentration region due to the stress-induced diffusion. ${ }^{25-27)}$ Furthermore, in a study of the influence of hydrogen accumulation at the crack tip, Gerberich and Chen assumed that fracture occurs when the local hydrogen concentration at the region where the hydrostatic pressure shows its maximum reaches a threshold limit for fracture, and proposed a model in which the threshold stress intensity factor is proportional to the ratio of local hydrogen concentration the crack tip and that at the part which is not affected by stress. ${ }^{28)}$ Although the present study did not determine whether hydrostatic pressure was present at the edge of the U-bent specimens, it seems reasonable to think that the hydrogen embrittlement threshold stress intensity factor $K_{H}$ would be influenced by that local accumulated hydrogen. Consequently, in order to understand the dependence of the diffusible hydrogen content on $K_{H}$ in detail, an interpretation considering the accumulation of diffusible hydrogen at the crack tip is an issue in the future.

\section{Conclusions}

The influence of the edge condition after shearing, applied stress, bending strain and diffusible hydrogen content on hydrogen embrittlement resistance in an UHSS sheet was investigated. The deterioration mechanism of hydrogen embrittlement resistance in an UHSS sheet with a sheared edge was also discussed. The results obtained in this study are summarized as follows:

(1) The fracture stress of the as-sheared specimens was 
lower than that of the ground specimen. It especially decreased in specimens which were bent so that the fracture surface was on the outer side. Critical fracture stress also decreased with increasing diffusible hydrogen content.

(2) The fractures in the as-sheared specimens occurred by propagation of the microcracks which were introduced at the edge of the specimen by shearing and bending.

(3) The fracture stress in the fracture surface specimens showed a further decrease when the bending radius was reduced, although that of the burnished surface specimens was independent of the bending radius. The reason why the fracture stress decreased in the fracture surface specimens was due to generation of larger cracks at the edge resulting from the reduction of the bending radius.

(4) Although the fracture stress in the as-sheared specimens decreased with increasing crack length, the decrement of fracture stress in a $\mathrm{pH} 4 \mathrm{HCl}$ solution was relatively smaller than that in $\mathrm{pH} 1$ and $3 \mathrm{HCl}$ solutions.

(5) When the results with or without fracture at each diffusible hydrogen content were arranged by the stress intensity factor $K$, the threshold stress intensity factor decreased with increasing diffusible hydrogen content.

(6) The reason why the critical fracture stress in a bent UHSS sheet with a sheared edge decreased in comparison with the ground specimen was considered to be because $K>$ $K_{H}$ was satisfied at a relatively lower stress due to generation of microcracks by bending at the edge which had been damaged by shearing.

\section{REFERENCES}

1) Y. Toji, K. Hasegawa, H. Shigemoto, H. Kawabe, T. Fujita, Y. Tanaka, H. Nakamura, H. Ishida and H. Sakamoto: Rev. Automot. Eng., 30 (2009), 159.

2) Y. Toji, K. Hasegawa, K. Kawamura, H. Kawabe and H. Shigemoto:
Materia Jpn., 48 (2009), 129.

3) S. Matsuyama: Delayed Fracture, The Nikkan Kogyo Shimbun LTD., Tokyo, (1989).

4) Y. Hosoya, S. Tsuyama, Y. Nagataki, S. Kanetoh, T. Izuishi and Y. Tanaka: NKK Tech. Rep., 145 (1994), 33.

5) Y. Toji, S. Takagi, M. Yoshino, K. Hasegawa and Y. Tanaka: Tetsuto-Hagané, 95 (2009), 887.

6) K. Hayashi, N. Fujita, S. Takebayashi, M. Takahashi and Y. Sakuma: Materia Jpn., 44 (2005), 254.

7) K. Hayashi, N. Fujita and M. Takahashi: CAMP-ISIJ, 18 (2005), 1559.

8) S. Takagi, Y. Toji, K. Hasegawa, Y. Tanaka, N. Rössler, B. Hammer and T. Heller: Int. J. Automot. Eng., 2 (2010), 7.

9) S. Takagi, Y. Toji, K. Hasegawa, Y. Tanaka, N. Rössler, B. Hammer and T. Heller: Mater. Sci. Technol. Conf. Exhib., (2010), No. 3, 1769.

10) M. Matsuno, H. Suzuki, K. Takai and Y. Hagihara: CAMP-ISIJ, 22 (2009), 1383, CD-ROM.

11) M. Matsuno, H. Suzuki, K. Takai and Y. Hagihara: CAMP-ISIJ, 23 (2009), 1285, CD-ROM.

12) K. Mori, Y. Abe and Y. Suzui: J. Mater. Process. Technol., 210 (2010), 653.

13) Standard Method for X-Ray Stress Measurement (2002) -steel edition- reprinted ed. by JSMS Committee on X-ray Study of Mechanical Behavior of Materials, The Society of Materials Science, Japan, Kyoto, (2006).

14) Y. Toji, S. Takagi, M. Yoshino, K. Hasegawa and Y. Tanaka: CAMPISIJ, 21 (2008), 1453, CD-ROM.

15) R. A. Oriani: Acta Metall., 18 (1970), 147.

16) T. Yamaguchi and M. Nagumo: ISIJ Int., 43 (2003), 514.

17) M. Nagumo, K. Ohta and H. Saitoh: Scr. Mater., 40 (1999), 313.

18) Y. Toji, S. Takagi, K. Hasegawa and K. Seto: ISIJ Int., 52 (2012), 274.

19) A. Dalloz, A-F. Gourgues, A. Pineau and J. Besson: Mater. Sci. Technol. Conf. Exhib., 1 (2007), 167.

20) Fédération Internationale de la Précontrainte: Report on Prestressing Steel: 5. Stress Corrosion Cracking Resistance Test for Prestressing Tendons, Vol. 5, Cement and Concrete Association, England, Slough, (1980).

21) S. Takagi, Y. Toji, M. Yoshino and K. Hasegawa: ISIJ Int., 52 (2012), 316.

22) S. Takagi and Y. Toji: ISIJ Int., 52 (2012), 329

23) T. Komamura and T. Shoji: Trans. Jpn. Soc. Mech. Eng., 61 (1995), 283.

24) H. A. Wriedt and R. A. Oriani: Acta Metall., 18 (1970), 753.

25) H. P. Van Leeuwen: Corrosion, 29 (1973), 197.

26) H. P. Van Leeuwen: Eng. Fract. Mech., 6 (1974), 141.

27) A. Nozue: Advances in Delayed Fracture Solution ed. by Division of Microstructure and Properties of Materials, ISIJ, Tokyo, (1997), 197.

28) W. W. Gerberich and Y. T. Chen: Metall. Trans. A, 6A (1975), 271. 